Volodymyr POLISHCHUK ${ }^{1}$, Miroslav KELEMEN ${ }^{2}$, Jarosław KOZUBA ${ }^{3}$

${ }^{1}$ Uzhgorod National University

${ }^{2}$ Technical University of Košice

${ }^{3}$ Silesian University of Technology (Politechnika Ślaska)

\title{
TECHNOLOGY IMPROVING SAFETY OF CROWDFUNDING PLATFORMS FUNCTIONING IN THE CONTEXT OF THE PROTECTION OF THE START-UP INVESTORS IN THE FINANCIAL AND TRANSPORT SECTORS
}

\begin{abstract}
The information technology models improving security functioning of crowdfunding platforms and advice on a new type of business were developed. The article solves the problem of safety of crowdfunding platform functioning based on developed models: rating assignment system of unified assessment crowdfunding platforms; startup projects assessment; startup projects risk assessment concerning their financing safety level and criminal law protection of investors against the financial fraud. The models are based on the correct usage of fuzzy logic and fuzzy set device to reveal the uncertainty of experts' consideration that insures authenticity of scientific results.
\end{abstract}

Keywords: crowdfunding platform; safety; risks; criteria, expert evaluation; protection of interests

\section{Introduction}

Today's experience shows that millions of people, who had nothing in common with investing, can invest money in start-ups and their economy. "Observing the development of a large number of start-ups, it is clear that using modern technology one can find a good alternative to lending" [13].

Crowdfunding - is investing in a start-up that is performed by a lot of people, including micro investors and business angels.

Crowdfunding has a great potential. In general, in every country there is a huge amount of money which are not used. Usually, a particular average person has not 
enough spare cash to think about the traditional investment. People do not invest a small amount of money but waste it. The world economy can get much more if small amounts of spare cash come in the development of the economy through crowdfunding platforms. If there are more funded start-ups, there are more work places, products and services they created.

Therefore, there is urgent primary task of improving the safety of crowdfunding platforms. It needs to be solved systematically by developing new models of information technology and the introduction of a reasonable law regulation and distribution of business [11] especially in the transport sector [14]. The secondary task is to strengthen the criminal protection of investors in the startup projects, which also do not avoid financial fraud. These aspects are not in line with the further safe and sustainable development of society, and required protection of interests. "Security and law-based research generally points to the "struggle" with the technical and the anti-social phenomena, which is complex, lengthy, demanding but socially necessary for the healthy, sustainable and sustainable development of a democratic society: state security and citizen security, protection of fundamental human rights and freedoms and other protected interests" [8]. There exist a wide range of scientific studies proving that the present understanding of human safety and security consists of several dimensions which might not be directly linked only to actual war activities but to ensure the security of protected interest $[2,4,5,10]$.

\section{Formulation of the issue}

The work is aimed to develop a model of increasing the security of crowd funding platforms. The development is based on eliminating the disadvantages of this type of investment. It is necessary to develop a model of information technology and legal advice on a new type of business. The model will improve the safety of platforms that will encourage the popularization of modern business and implement new technologies.

What specific research questions are being tackled? For the first time the model of rating assignment system of unified assessment crowdfunding platforms; For the first time criminal law protection of investors against the financial fraud was systematized and outlined; mathematical model of information technology for reducing the fraud risk of startup projects which are presented at the platform related to their financing safety level was improved; further development of recommendation concerning reducing of commonly known investment disadvantages by using crowdfunding platforms was obtained. 
The main disadvantages of crowd funding are:

1. "The risk of fraud: possibly, under the guise of start-up pyramid scheme gathers the capital or the platform itself is created for phishing scams.

2. The risk that the required amounts of investments will not be collected and the project will not be implemented.

3. The risk that the project will be unprofitable and closed, and the investment will be lost.

4. In many cases, crowdfunding schemes do not correspond to the legislation of the country, which does not allow to resolve the disputes in court in fairness.

5. Unprofitability - many platforms are closed soon after they were opened." (https://simex.bz/about, http://crowdconsulting.ru).

There is a direct correlation between platform safety level, the submitted projects and the number of investments made. Therefore, it is necessary to develop scientific approaches to eliminate the disadvantages of crowdfunding that will improve the safety level of modern investment platforms.

\section{The purpose and objectives of the study}

The purpose of the paper is the development of technologies improving safety of crowdfunding platforms functioning within the "fight" against the financial fraud. Provided we want to protect a subject (a certain interest) in an effective way, we have to study and research the subject, its surroundings and the relationships among them $[7,9]$.

To reach the aim of the research it is necessary to solve the following problems:

- to give recommendations to eliminate the disadvantages of this type of investment,

- to develop a mathematical model of information technology to reduce the risk of fraud in start-ups presented; on the platform regarding the level of security of its funding,

- to create a rating system model of the crowdfunding platforms in order to reduce the risk of fraud.

\section{Methodology and what is novelty}

Research methods. To solve the given task we used methods of system analysis; theory of fuzzy set in the construction of the model for risk assessment of startup projects and uncertainty disclosure and increase in authenticity of expert 
consideration; multicriterion evaluation methods to build a model of rating assessment of crowdfunding platform.

Scientific novelty of the results. In the work solved the problem of applied scientific development of the fraud risk reducing model in startup projects and crowdfunding platforms that in conjunction is a safety improvement technology of crowdfunding. Based on the theoretical and practical research, the following results were obtained:

For the first time the model of rating assignment system of unified assessment crowdfunding platforms based on aggregated assessment of platform owners', integrated risk assessment related to security level of project financing, aggregated investors' assessment and evaluation of realized projects success were developed.

For the first time criminal law protection of investors against the financial fraud was systematized and outlined; mathematical model of information technology for reducing the fraud risk of startup projects which are presented at the platform related to their financing safety level was improved; further development of recommendation concerning the reducing of commonly known investment disadvantages by using of the crowdfunding platforms was obtained.

\section{Technology improving safety of crowdfunding platforms functioning}

\subsection{Recommendations for reducing the disadvantages of crowdfunding investment}

The first disadvantage is the risk of fraud.

Either platform that attracts investment in non-existent projects or start-ups presented in the form of pyramid scheme can turn out to be scammers. Therefore, it is necessary to reduce the risks of fraud. The main tools for platform security are:

- Accreditation - the platform must meet the legal requirements, to be registered and obtain a state license.

- Rating System - unified evaluation obtained on the basis of characteristics system. These indicators may include the assessment of platforms owners; the rating of start-ups; the estimation of investors; the indicators of successful performance.

Rating of platform should be assigned automatically while in operation and updated in real time. The metrics of ranking must be dynamic. It is necessary to develop a mathematical model to calculate the rating and information technology. 
The main means of safety improving and reducing the risk of fraud for startup projects are the following:

- Evaluation of start-ups to selection them for the platform to prevent access of fraudulent pyramid schemes to the platform. "Evaluation model of startups in case of information uncertainty" described in can be used to assess start-ups.

- Development of a mathematical model of information technology of risk assessment start-ups relating to safety of their financing, using fuzzy math.

Development of technologies of this type will enable us to consider the projects adequately, to increase the validity of investments decisions, and to increase economic and management security. This will allow to evaluate projects that are registered on the platform. Investors will be able to make informed investment decisions.

Increasing of platform security is possible with the help of its accreditation and rating system that will be displayed on the website, and assess of start-ups and their risk related to security funding level.

The disadvantages described in chapter 2 points 2-3 can be solved as follows. The platform should enable an investor to resell its investment in secondary trading. If there is a need to send back their investments before the launch of the project, or on the contrary to maximize profits at the peak of popularity of the project, it should be possible to sell the investment share in secondary trading. Therefore, the successful sale of investment shares allows to make an additional profit. The platform should be able to refund. In case the investment project did not assemble the declared amount of money, the investments should be sent back into investor's account without platform commissions.

Point 4 should be solved systematically developing legislation for a new type of IT maintenance business that has great prospects. Laws should be simple, clear and start-ups and investors supporting. Investors should not be afraid to be unable to bring their investments into projects during the successful launch phase. And "the start-uppers" have to be sure that in case of successful project launch the investors will not get their business. There should be a clear law that governs modern business and prevents fraud.

If disadvantages described in points 1-4 are solved systematically, the unprofitability of platforms is automatically reduced. 


\subsection{Mathematical model of risk start-up assessment concerning the funding safety level}

Let us develop a two-level mathematical model of information technology enabling each start-up on the platform to establish a start-up risk assessment of the project realization, on which the safety level of its future funding depends.

Let us offer our last experience based on the previous work [12] and for example [1] the next set of start-up risk assessment criteria on which the platform can assess risks of start-ups. There are four groups of criteria: $K^{O}-$ «operational risk»; $K^{I}-\left\langle\right.$ investment risks»; $K^{F}-\left\langle\right.$ financial risks»; $K^{S}-\langle$ risks of innovation».

Let us present each group of criteria as a set parameters. For instance, a «risks of innovation» criteria - $K^{S}$ is expressed using indicators: $K_{1}^{S}$ - risk of inefficient innovative investments; $K_{2}^{S}$ - risk of inefficient innovation promotion; $K_{3}^{S}$ - risks of terms disruption of innovation design; $K_{4}^{S}$ - risks of technology innovation; $K_{5}^{S}-$ the risk of resource deficiency in innovation design.

Each risk criteria is evaluated by experts with one of the terms of the following term-set of linguistic variables $L=\left\{\begin{array}{lll}H ; & H C & C\end{array} \quad B C ; \quad B\right\}$, where: $\mathrm{H}-$ «low risk level»; $\mathrm{HC}-$ «risk level below average»; $\mathrm{C}$ - «average risk level»; $\mathrm{BC}-$ «risk level above average»; $\mathrm{B}-$ «high risk level».

Also, an expert puts the number of «authenticity» for each assessment of risk level $\mu(L)$ of his consideration concerning the interval $[0 ; 1]$. Thus, the input data for risk assessment projects of different origins can be presented in tables by the following criteria risk groups (tab. 1).

Table 1

The input data by the criteria risk groups

\begin{tabular}{|c|c|c|}
\hline Group criteria's & Linguistics variable & Accuracy of expert considerations \\
\hline$K_{1}^{\alpha}$ & $L_{1}^{\alpha}$ & $\mu\left(L_{1}^{\alpha}\right)$ \\
\hline$K_{2}^{\alpha}$ & $L_{2}^{\alpha}$ & $\mu\left(L_{2}^{\alpha}\right)$ \\
\hline$\ldots$ & $\ldots$ & $\ldots$ \\
\hline$K_{m}^{\alpha}$ & $L_{m}^{\alpha}$ & $\mu\left(L_{m}^{\alpha}\right)$ \\
\hline
\end{tabular}

Where $\alpha=\{O ; I ; F ; S\}-$ one of the risk criteria group, $K_{i}^{\alpha}, i=\overline{1, m}-i$-indicator of risk group criteria, $L_{i}^{\alpha}$ - indicator of term-set $L$ for $i$-indicator of the group $\alpha$, 
$\mu\left(L_{i}^{\alpha}\right)$ - the accuracy of expert considerations concerning appropriation of variable $L_{i}^{\alpha}$ corresponding value.

Let us describe two-level mathematical model of projects risk assessment based on the input of linguistic variables. It's necessary to make up rules of the knowledge base belonging to get the resulting term-evaluation $L^{\alpha}$ for each risk criteria group on the first level. On the basis of the resultant term assessment $L^{\alpha}$ let us define the aggregated estimate of reliability $\mu\left(L^{\alpha}\right)$. At the second level on the basis of the estimates $L^{\alpha}$ and $\mu\left(L^{\alpha}\right)$ let us make a project risk assessment for each group of criteria $\alpha$.

Consider the first level - building of association rules of resulting term assessment by risk criteria group.

Level $H-« l o w$ risk level». The minimum amount of criteria with low risk level term should not be less than $60 \%$ and the remaining $40 \%$ of the criteria should not have terms lower than «risk level below average».

Level $H C$ - «risk level below average». The project should have the minimal amount of criteria with the term «risk level below average» not less than $60 \%$, and the other $40 \%$ of criteria should have terms not lower than the «average risk level».

Level $C$ - «average risk level». The minimal amount of criteria with the term «average risk level» not less than $60 \%$, and the other $40 \%$ of criteria should have terms not lower than the «risk level above average».

Level $B C$ - «risk level above average». The minimal amount of criteria with the term «risk level above average» not less than $60 \%$, and the other $40 \%$ of criteria should have terms not lower than the «high risk level».

Level $B$ - «high risk level». The project gets the resulting term-evaluation «B»» in case the amount of criteria with the term «high risk level» compiles $60 \%$ and more.

A know ledge base is built based on accessory rules of the resulting termevaluation due to the risk criteria groups.

Since the expert gives every $L_{i}^{\alpha}$ variable the authenticity he considers $-\mu\left(L_{i}^{\alpha}\right)$ from interval $[0 ; 1]$, than linguistic variables can be presented as triangular membership functions according to Kofman, A. 1983. In this case every linguistic $L$ variable can be replaced with the next $L^{*}$ with authenticity $\mu\left(L^{*}\right)=1-\mu(L)$. That makes it possible to draw out all the possible variants of the expert risk assessment with the help of the membership rules of the resulting term-evaluation.

The aggregated authenticity estimation $\mu\left(L^{\alpha}\right), \alpha=\{O ; I ; F ; S\}$ is calculated with the following formula: 


$$
\mu\left(L^{\alpha}\right)=\frac{1}{n} \sum_{i=1}^{m} \mu\left(L_{i}^{\alpha}\right), \alpha=\{O ; I ; F ; S\}
$$

Where $\mu\left(L_{i}^{\alpha}\right)$ - is the authenticity estimation of the linguistic variables which match the resulting term-evaluation for $i$-criterion of $\alpha$ risk criteria group; $n-$ is their amount.

Thereby, the resulting term-evaluation for every risk criteria group of a project based on membership rules and the aggregated authenticity estimation is obtained on the first level (1).

The aggregated risk estimation and its linguistic interpretation concerning the safety of investing in start-ups is obtained on the second level.

Since the resulting term-evaluation $L^{\alpha}$ contents risk level, its terms can be adequately determined on the percentage scale $(0-100 \%)$, where each one is given the value on the interval $[a ; b]$. For instance, " $H$ " $-[0 ; 20]$, " $H C$ " $-[20 ; 40], " C$ " $-[40 ; 60], " B C "-[60 ; 80], " B "-[80 ; 100]$. The risk of $90 \%$ is interpreted as «high risk level».

The relation between the resulting $L^{\alpha}$ term-evaluation and its authenticity $\mu\left(L^{\alpha}\right)$ will be seen as a $S$-shaped membership function. As the membership function values (the aggregated risk estimation) and the intervals of numerical values for $L$ are defined, for every criteria group $\alpha, x^{\alpha}$ is deduced from the general formula of the $S$-shaped membership function:

$$
x^{\alpha}=\left\{\begin{array}{cc}
\sqrt{\frac{\mu\left(L^{\alpha}\right)}{2}}(b-a)+a, & 0 \leq \mu\left(L^{\alpha}\right) \leq 0.5 ; \\
b-\sqrt{\frac{1-\mu\left(L^{\alpha}\right)}{2}}(b-a), & 0.5<\mu\left(L^{\alpha}\right) \leq 1 .
\end{array}\right.
$$

To get the generalized risk evaluation of the start-up project for the criteria group $\alpha$ the following formula is used:

$$
z^{\alpha}=\frac{x^{\alpha}}{100}
$$

The evaluation $z^{\alpha}$ is normalized. It presents the aggregated risk estimation of the start-up concerning the resulting term-evaluation and its authenticity for every criteria group $\alpha$.

Let us calculate the aggregated risk estimation for all criteria groups $\alpha$ : 


$$
O_{R}=\frac{1}{4} \sum_{\alpha}\left(1-z^{\alpha}\right)
$$

The gained estimation $O_{R}$ is normalized. To compare it with the output variable $R$ the following scale is suggested:

$r_{1}=$ «negligible risk level of start-up and high level of its funding safety»;

$r_{2}=$ «low risk level of start-up and the level of its funding safety above average»;

$r_{3}=$ «average risk level of start-up and average level of its funding safety»;

$r_{4}=$ «high risk level of start-up and low level of its funding safety»;

$r_{5}=$ «extreme risk level of start-up and extremely low level of its funding safety».

The linguistic interpretation of the aggregated risk estimation $R=\left\{r_{1}, r_{2}, r_{3}, r_{4}, r_{5}\right\}$ is defined by the following scale: $O_{R} \in(0,77 ; 1]-r_{1} ; O_{R} \in(0,57$; $0,77]-r_{2} ; O_{R} \in(0,36 ; 0,57]-r_{3} ; O_{R} \in(0,21 ; 0,36]-r_{4} ; O_{R} \in[0 ; 0,21]-r_{5}$.

The model of creating the aggregated risk estimation of a start-up uses the expert consideration and considerations, based on the result, are aggregated in the final estimation by the criteria groups.

\subsection{The model of crowdfunding platform rating estimation}

For the rating appropriation system of the unified estimation to work it is necessary to develop a mathematical model of its calculating on the website of the crowdfunding platform. Such rating model should be standardized for crowdfunding platforms at least within the state. Investors and start-uppers should have the complete analytical and rating information about the platform.

The model of the task is formulated as follows:

$$
E K=P R\left(P R_{1}, P R_{2}, P R_{3}, P R_{4}\right)
$$

where:

$P R_{1}$ - aggregated estimation of the platform wrens,

$P R_{2}$ - in targeted risk estimation concerning the project's funding safety level,

$P R_{3}$ - aggregated estimation of investors who worked on the platform,

$P R_{4}$ - success estimation of the realized projects,

$E K$ - output rating and linguistic estimation of the crowdfunding platform,

$P R$ - operator that makes the output $E K$ variable corresponding to input estimations $P R_{1}, P R_{2}, P R_{3}, P R_{4}$. 
A set of criteria in the form of expert questions is suggested to get platform owners aggregated evaluation. Also appropriate tonal estimates range is described. Platform owners answer the questions and choose the most appropriate option.

$K_{1}^{P}$ - Platform holders comprehensive income in the last 12 months?:

1. $\$ 0$ - $\$ 24999$ (5 points);

2. $\$ 25000$ - $\$ 99999$ (20 points);

3. $\$ 100000$ - $\$ 249999$ (25 points);

4. $\$ 250000$ or more (30 points).

$K_{2}^{P}$ - Platform owners business experience level is achieved due to?:

1. lack of business keeping knowledge (5 points);

2. successful small business launch (15 points);

3. working as co-founders or co-workers in a successful high-tech company (20 points);

4. there is the founder of several successful companies among the owners (30 points).

$K_{3}^{P}$ - The owners are experienced in IT or investment market occupying executive positions in the branch?:

1. none of the owners is (5 points);

2. less than 2 years ( 15 points);

3. 2-5 years ( 20 points);

4. has an experience for over 5 years (30 points).

$K_{4}^{P}$ - The number of scientists working on a platform development full time for at least three months?:

1. none (5 points);

2. a group of $1-3$ (15 points);

3. a group of $3-5$ (20 points);

4. more than 5 (30 points).

$K_{5}^{P}$ - The number of sales / marketing development / business experts working to promote the platform full-time for at least three months?:

1. none (5 points);

2. a group of $1-3$ (15 points);

3. a group of 3-5 (20 points);

4. more than 5 (30 points).

$K_{6}^{P}$ - The authorized capital of crowdfunding platform is?:

1. $\$ 0$ - $\$ 24999$ (5 points);

2. $\$ 25000$ - $\$ 99999$ (20 points);

3. $\$ 100000$ - $\$ 249999$ (25 points);

4. $\$ 250000$ or more (30 points). 
$K_{7}^{P}$ - Corporate attorney of platform is:

1. the lawyer with only a law degree (5 points);

2. a small local firm (10 points);

3. a medium sized company, which operates in the investment area (20 points);

4. a nationally recognized corporate law firm with a lot of connections in the venture community (30 points).

The following scale for the answers scores is heuristic and characterizes the level of the platform owners. The more points there are, the more trust the platform and its owners have. For each criterion the platform and its owners correspond to one of the answers to which the corresponding scores assigned. Let us define the assessments convolution, such as the amount of tonal range answers points divided into the amount of maximum points:

$$
P R_{1}=\frac{\sum_{i=1}^{7} b_{i}}{\sum_{i=1}^{7} b_{i}},
$$

where:

$b_{i} \quad$ - scoring by the $i$-criterion,

$b_{i}$ - maximum scoring by the $i$-criterion, $\max$

$P R_{1}$ - normalized aggregate assessment of the platform owners.

To get an integrated risk assessment regarding the project funding security level let us use the following formula:

$$
P R_{2}=\frac{\sum O_{R}}{d}
$$

where:

$O_{R}$ - start-up risk assessment (described in the previous point),

$d-$ a number of start-ups on a platform.

The next step is building of an aggregated assessment of investors working with a platform $-P R_{3}$. Thus, let us sum up the assessment of the presence of the following subject son the platform:

1. Venture fund which is a part of the top 20 global investors $(0,4$ points). 
2. Worldwide-known business angels ( 0,3 points).

3. Large national investment firms ( 0,2 points).

4. National-known business angels ( 0,1 points).

$P R_{3}$ assessment obtained by summing the number of points will be normalized. Of course, such concepts as "top 20" or "known business angels" are fuzzy. A knowledge base, which is based on the world rankings, should be created to build up a computer information technology based on the proposed model. It has to be updated every time when new rankings are published.

To get $P R_{4}$ - the assessment of accomplished project success the following formula is suggested:

$$
P R_{4}=\left\{\begin{array}{cc}
R_{4}, & R_{4}<1 \\
1, & R_{4} \geq 1
\end{array}\right.
$$

where:

$R_{4}=\frac{k^{*}}{n_{0}}, k^{*}$ - the amount of projects on the platform which raised the start-up budget and got the investments,

$n_{0} \quad-$ the amount of projects which didn't raise the start-up budget.

At this point, let us build about going rating and linguistic assessment of crowdfunding platform $E K$. If an expert defines weight coefficient $\left\{w_{1}, w_{2}, w_{3}, w_{4}\right\}$ of an interval. Normalized weight coefficients should be defined as follows:

$$
\alpha_{i}=\frac{w_{i}}{\sum_{i=1}^{4} w_{i}}, i=\overline{1,4}, \sum_{i} \alpha_{i}=1
$$

Let us use the following formula to rate the scoring:

$$
P R=\sum_{i=1}^{4} \alpha_{i} \cdot P R_{i}
$$

The obtained $P R$ assessment is set from the interval [0;1], the following scale is suggested to compare it with its outgoing variable $E K: e k_{1}=$ «very high platform rating»; $e k_{2}=$ «high platform rating»; $e k_{3}=\left\langle\right.$ sufficient platform rating»; $e k_{4}$ $=\left\langle\right.$ speculative platform rating»; $e k_{5}=\langle$ (very low platform rating»». 
The linguistic explanation of the aggregated risk assessment $E K=\left\{e k_{1}, e k_{2}, e k_{3}, e k_{4}, e k_{5}\right\}$ is defined as follows: $P R \in(0,87 ; 1]-e k_{1} ; P R \in$ $(0,67 ; 0,87]-e k_{2} ; P R \in(0,36 ; 0,67]-e k_{3} ; P R \in(0,21 ; 0,36]-e k_{4} ; P R \in[0 ;$ $0,21]-e k_{5}$.

How did we select criteria for experts? Are criteria we suggest somehow related to good/bad practices of crowdfunding? Based on analysis and practical experience, the set of criteria for obtaining the unified rating assessment of crowdfunding platforms was given and the set of criteria for startup projects risk assessment was suggested. The sets of criteria are heuristic and they can be supplemented when needed. Information technology models do not depend on the number of criteria. Therefore, the number of criteria does not affect the work of developed models and increase in their number during the technology implementation leads to more accurate estimates.

Thus, the building model of the crowdfunding rating assessment is given. The program realization of the models hold gets the information from the platform and should be its inseparable addition. It gives the opportunity to assign the platform rating based on the dynamic indicators in real time.

\section{Criminal law protection of investors against the financial fraud}

The authors of start-up projects may commit the unlawful actions, such as the fraud that intentionally causes the damage. The damage under the Criminal Code means the damage to property or actual loss of property or the rights of the victim or other harm that is related to a criminal offense, whether damage to property or rights.

The damage may be caused to an investor who may be a natural person or a legal entity. In the case of drawing funds from different funds, it may also be a grant, subsidy or start-up project contribution, and so on. Subsidiary fraud can be committed at the national level, or the offender may commit a crime of damaging the interests of the European Union, and so on. Such actions are primarily among the crimes against the property.

The criminal law protection of property rights is regulated primarily in the Fourth chapter of the Special part of the Criminal Code, but also on the basis of Art. 20 sec. 1 of the Constitution of the Slovak Republic no. 460/1992 Coll., According to which everyone has the right to own property. The property rights and interests are also protected in some other headings of the specific part of the 
Criminal Code, such as the economic, generally dangerous and environmental crimes. The laws protect not only tangible property but also intangible property.

The Criminal Law Theory classifies crimes against property $(\S 212-\S 249 a)$ into three groups:

1. Crimes that are associated with the unauthorized enrichment,

2. Crimes related to damage to the foreign property and property rights,

3. Crimes in which the booty from crimes are involved.

The group object of the fourth chapter of the Special part of the Criminal Code is property rights, but also some other property rights and undisturbed possession of the thing. The subject of the attack is usually an alien thing.

The factual nature of the crime of fraud is defined in the provisions of $\S 221$ par. 1 of the Criminal Code:

"Whoever enriches himself or herself by causing anyone to mislead or mislead a person to cause damage to another's property, causing minor damage to foreign property, shall be punished by imprisonment for up to two years ... Deprivation of liberty for ten to fifteen years The offender shall be punished if he commits the offense referred to in paragraph 1 as a member of a dangerous group." [3].

An assessment of whether, in a particular case, all the constituent elements of the offense are met by the law enforcement and, ultimately, the court.

$\S 261-\S 263$ of the Criminal Law "The Damage to the European Union's Financial Interests" provides protection of the financial interests of the European Union in the territory of the Slovak Republic in accordance with the European Association Agreement concluded between the European Communities and their Member States and the Slovak Republic dated 4.10.1993, Which entered into force on 1.2.1995. Another important document in this area is the Convention on the Protection of the European Communities' Financial Interests of 26.7.1995, the Protocol to that Convention of 27.9.1996 and the Second Protocol to the Convention of 19.6.1997.

The object of these crimes is to protect the financial interests of the European Union and to harm the financial interests of the European Union "Core crimes", which by their very nature are most jeopardizing the interests of the European Union and its citizens in relation to the threat to the four freedoms on which the European Union is built.

The perpetrator of the crimes under $\S 261$ and 263 may be anyone. The perpetrator under $\S 262$ may be only a managerial or controlling officer.

The subjective aspect of crimes under $\S 261$ and 262 presupposes the culpability in the form of intent and the crime in the form of negligence for a crime under $\S 263$. 


\section{Results and discussion}

The result of scientific research is the designed models of fraud risks reducing in the start-ups and crowdfunding platforms. Altogether they build a safety improving technology of the crowdfunding.

Is our model similar to existing one? Crowdfunding has a range of commonly known disadvantages and their reducing can improve and develop new type of business activity. The information technology models is a new ideological approach that does not have analogue. The system solves the problem of safety of crowdfunding platform functioning based on developed models: rating assignment system of unified assessment crowdfunding platforms; startup projects assessment; startup projects risk assessment concerning their financing safety level and criminal law protection of investors against the financial fraud. The models are based on the correct usage of fuzzy logic and fuzzy set device to reveal the uncertainty of experts' consideration that insures authenticity of scientific results.

Given recommendations of the weaknesses elimination in conjunction with the developed technology are aimed at the encouraging of the crowdfunding business promotion and development.

What formulations are valid now, what amendments are suggested? Crowdfunding is a kind of very risky innovative business which needs development and implementation of new assessment technology and fraud detection. Therefore, let us suggest the following:

The disadvantages solving should be implemented carefully in order not to harm the development of new business:

1. Laws must be simple (it means they should not be ambiguous), laws must be clear and aimed at the start-ups support but protected the investors against the financial fraud as much as possible too;

2. Accreditation of the crowdfunding platform should take place when it is registered with the relevant authorities;

3. Platform rating should be assigned automatically, updated in real time and displayed on platform site;

4. Start-ups evaluation and fraud risk assessment should be promulgated while choosing the project.

Thus, the proposed improving safety crowdfunding platform technology has many advantages, namely: mathematical information technology model of the reducing the start-up project fraud risk increases objective expert estimates of project risk assessment using the input linguistic variables and reliability of the expert considerations concerning their assignment; makes it possible to change the decision-making level in the knowledge base; brings together opinions by criteria 
groups in the final evaluation and risk degree of the project, based on the two-level fuzzy mathematical model; the rating system of crowdfunding platform model can evaluate the platform and give the linguistic interpretation of such evaluation using a system approach of the platform owners, start-ups risks, investors and successful projects.

The disadvantages of this approach include the use of different membership functions models and convolution that leads to ambiguous results.

Platform owners can select the perspective projects for their customers, avoiding the scams. Startups and entities, which wish to invest in them, will be able to choose a platform on the rating level. This agenda can help ensure the security and sustainability of the society's development, which is the subject of research by other scientists for example $[6,15]$ etc.

\section{Conclusions}

The research of a crowdfunding platform functioning is conducted and the technology of improving the security of investing in start-ups on the platform is proposed. The following results were obtained:

- the recommendations on the elimination of five known crowdfunding disadvantages are given, namely: fraud risks, legal risks, platform and project unprofitability, non-investment of the required amount of money to run the project;

- there is a developed mathematical model of information technology for fraud risks reducing in start-up using expert arguments on assessments by different risk criteria, reliability of its reasoning and based on the opinion aggregation of criteria groups in the final evaluation;

- there is a created model of the crowdfunding platform rating system to reduce the fraud risk. This model allows evaluating the platform and giving a linguistic interpretation of such evaluation, aggregating considerations on expert estimates: the platform owners; the project financing safety risk; the investors working with a platform; the projects successfulness.

Thus, the technology of crowdfunding safety improving based on the model of fraud risks reducing in the start-ups and platforms, as well as recommendations on elimination of existing disadvantages, will be a useful tool for promotion of the crowdfunding platforms activities and within the support tools against the financial fraud in the financial and transport sectors too. 


\section{References}

1. Abdulayeva Z.I., Niedosekin A.O.: Stratehycheskyy analyz ynnovatsyonnykh ryskov. Sankt-Peterburg, Izdatielstvo Polytekhn, 2013 [Strategic analysis of innovation risks].

2. Balatka M. et al.: Exposure of the environment and surface water by dangerous liquid - the slop outflow model. In: Proceedings Volume III The 15th World MultiConference on Systemics, Cybernetics and Informatics July 19th - July 22nd, 2011 Orlando. Florida, USA. International Institute of Informatics and Systemics, 2011.

3. Criminal Code of the Slovak Republic. Available at: https://www.slov-lex.sk/pravnepredpisy/SK/ZZ/2005/300/

4. Dvořák Z. et al.: Enhancing of security on critical accident locations using telematics support. In: ICSIT $2010=$ International conference on society and information technologies: proceedings April 6th-9th, 2010 - Orland. Florida, USA: International Institute of Informatics and Systemics, 2010.

5. Fuchs P. et al.: Simulation of dangerous substances outflows into the environment because of traffic accidents by dangerous substances transport. In: WMSCI 2010: the 14th world multi-conference on systemics, cybernetics and informatics: proceedings volume 1: June 29th - July 2nd, 2010 Orlando. Florida, USA: International Institute of Informatics and Systemics, 2010.

6. Kabát L., Filip S., Filipová L.: Safety measurement peculiarities in selected countries. Journal od Safety and Sustainability, Iss. 6(3), 2017.

7. Kelemen M., Blišt’anová M.: Logistic Modelling to handle the Threat of Floods- The Bodva River example. In: SGEM 2014: 14th International Multidisciplinary Scientific GeoConference: Conference Proceedings: Volume III: 17-26 June, 2014. Sofia, Bulgaria: STEF92 Technology, 2014.

8. Kelemen M.: Criminogenic factors and criminal law protection of persons, property and security interests. Monograph. Belianum, Matej Bel University Publishing House. Banská Bystrica 2018.

9. Kelemen M.: Vybrané problémy ochrany osôb, majetku a d’alších chránených záujmov v sektoroch bezpečnosti. Monograph. Bratislava: VEDA SAV, 2014. [Selected issues of protection of individuals, property and other protected interests in the security sectors].

10. Kompiš V. et al.: Parallel computational models for composites reinforced by CNTfibres. In: Engineering Analysis with Boundry Elements. Mississippi USA: Elsevier, 2012. Vol. 36, No. 1, 2012.

11. Mal'ar M., Polishchuk V., Sharkadi M.: Model of information technology project financing risk assessment. Radio Electronics, Computer Science, Control, Vol. 3, No 4(81), 2016.

12. Malyar M., Polishchuk V., Sharkadi M., Liakh I.: Model of start-ups assessment under conditions of information uncertainty. Eastern European Journal of Enterprise Technologies, Mathematics and cybernetics - applied aspects. 2016. Vol 3/5 (81). 
13. Polishchuk V.: Tekhnolohiya zmenshennya ryzyku roboty venchurnykh fondiv. In Mizhnarodna shkola-seminar «Teoriya pryynyattya rishen». 8, 221. Collective monograph. [Technology to reduce the risk of venture funds. International Summer School "Decision theory"].

14. Soušek R. et al.: Doprava a krizový management. University textbook. First edition. Pardubice: Institut Jana Pernera, 2010. [Transport and crisis management]

15. Teivans-Treinovskis J.S., Amosova J.: Some aspects of criminal environmental impact on sustainable entrepreneurship activities, Journal od Safety and Sustainability, Iss. 4(1), 2016. 